\title{
Contradiction Medium and the Existence Question ${ }^{\dagger}$
}

\author{
Tianqi Wu \\ School of Humanities and Social Sciences, Xi'an Jiaotong University, Xi'an 710049, China; \\ tianqi1262016@mail.xjtu.edu.cn; Tel.: +86-1357-252-5265 \\ + Presented at the Fourth International Conference on Philosophy of Information, Berkeley, CA, USA, \\ 2-6 June 2019.
}

Published: 15 May 2020

\begin{abstract}
The process of human understanding of the world starts from viewing complex chaos, proceeding to monism followed by the contradiction theory, and finally returning to complexity theory, but without giving up the pursuit of monism. Lao-Tzu and Heraclitus put forward their own theories of unity of opposites at almost the same time. The thought of unity of opposites has long been contained in the theory of yin and yang and the Book of Changes. In the ontology of information evolution, existence and nonexistence (you and wu in Chinese) can also be roughly interpreted as a contradictory relationship. Existence and nonexistence are two opposing worlds. Our understanding of existence needs medium. We can only indirectly grasp the current meaning of existence after the transmission of multilayer mediums and the distortion and loss of information. Aristotle mentioned the notion of medium, but the real world cannot be explained by his ideas. All transformational processes of existence rely on medium. The transformation process of existence and nonexistence is different from the transformation process in the domain of existence. There is no need to rely on medium.
\end{abstract}

Keywords: unity of opposites; contradiction; medium; philosophy of information; existence (you in Chinese); nonexistence (wu in Chinese)

\section{Introduction}

The process of human understanding of the world starts from viewing complex chaos, proceeding to monism followed by the contradiction theory, and finally returning to complexity theory. However, the pursuit of the "grand unified theory", the core of which is monism, has never been abandoned. "Yi-ology", the oldest theory in ancient China, is a method of divination. Zhou Yi (the Book of Changes) is a book introducing divination. Astrology, oneiromancy techniques, shamanism or any other ancient religions and occult activities undeniably all share the important aspect of divination, which guides human behavior and helps people to make decisions. The simplest theory to explain the world is monism, so human civilization spontaneously began with it.

If myths are the beginning of human civilization, almost all human myths start with the separation of the sky and earth, marking the beginning of chaos. Thus, humankind believes that the world was a whole in the very beginning [1]. The ontological aspect of myths are monist in nature, and the creation of the world in myths is a process in which many things are generated from one single thing. This tradition of thought was inherited by ancient philosophies and can be seen in their works, such as the water origin theory of Thales, the idea of Plato, "Tao" of Lao-Tzu, the "Qi" origin theory in the pre-Qin period, the absolute idea of Hegel, the God in religion and so on.

\section{The Proposal of the Unity of Opposites}

On the one hand, Heraclitus believed that fire is the fundamental element of the world, and this is a standard version of monism. On the other hand, he was aware of the endless movement and 
changing of things, and he said: "Everything changes and nothing remains still... and... you cannot step twice into the same stream [2]." Things turn into their opposites all the time: "all things come into being by conflict of opposites [3]." The harmony of the world is produced in antagonism. These binary opposites can be regarded as the forefather of Western contradictions.

A similar thought also appeared in ancient Eastern civilization-yin and yang, as two opposing concepts, appeared very early in ancient Chinese civilization. However, in the beginning, yin and yang were only explained as two forces of nature [4]. Until Zhou Yi, relative concepts such as yin and yang; tian and di (heaven and earth); qian and kun (the universe) emerged, and they were regarded as the origins of the world. In Zhou Yi, the world was described as "tian and di [5]". There are some opposite concepts often mentioned in Zhou $\mathrm{Yi}$, such as inside and outside, up and down, hard and soft. Zhou Yi respects the thought of harmony, so it advocates to combine heaven and earth, allowing yin and yang to be reconciled, subsequently achieving a peaceful civilization. At the same time, this kind of thinking was also used to describe the attitude and cultivation of humans. The basic conditions for being a man with noble character are that he must be hard inside and soft outside; strong inside and gentle outside [5]. Zhou Yi is full of the idea of using opposing concepts to explain the world, and this thinking mode of contradiction also became a classic Oriental philosophy.

Lao-Tzu further developed the idea of contradiction in Daodejing: people prefer beautiful things because ugly exists; they admire good things because bad things spread. Thus, like "you" (existence) and "wu" (nonexistence), numerous other pairs of concepts are mutually dependent even though they are opposite, such as the difficult and the easy, the long and the short, the up and the down, the sound and the tone, etc. From this passage it can be seen that Lao-Tzu also used the idea of the unity of opposites to explain the mutual transformation, unity and harmony between "you" and "wu". "You" and "wu" not only appear together, but only through their relation to their opposite (each other) can they be compared, understood and ultimately manifested.

Not only that, Lao-Tzu also thought that the two opposite parties are mutually penetrated and interdependent: "All things are within the complex of yin and yang, which can be combined together in all things to produce harmony." Lao-Tzu thought that everything contains the opposing two elements of yin and yang, and that they are reconciled and united in all things. He said: "Tao gave birth to the One; the One gave birth successively to two things, three things, up to then thousand." which means that Tao gave birth to the absolute "One", the "One" gave birth to yin and yang, and finally everything else was born from the activity of yin and yang. Lao-Tzu then applied this idea to his life principle theory. How big of a difference is there between a respectful response and an indifferent response? What is the difference between good and evil? [6] Luck hides in misfortune, while misfortune lurks in luck. If you want to restrain it, you first have to expand it; to weaken it, strengthen it first; to dethrone it, first allow it to thrive; to take it, give it first.

\section{The Unity of Opposites and Medium}

In contemporary philosophy of information, existence and nonexistence can also be interpreted roughly as the unity of opposites mentioned in the previous article. Existence and nonexistence are two opposing worlds. We need to rely on existence to understand the concept and scope of nonexistence, and nonexistence is the home to return for existence after it dies out and the possible future for the evolvement of existence, and thus the relationship between existence and nonexistence is similar to the unity of opposites. However, they are not pure opposites, and they come from two separate worlds with no intersection [7]. The evolution of existence is self-sustaining and does not depend on nonexistence. Nonexistence as absolute nothingness has neither evolution nor function and reaction. The transformation between existence and nonexistence is different from the interaction in the realm of being, and there is no medium between them.

We can understand Heraclitus's confusion about the change of this world, which leads to the extreme state of the mind, in this rapidly changing development of the world. Our understanding of existence requires medium, after the transmission of multi-layer medium, the distortion and loss of information, we really cannot grasp the true meaning of the present existence. So only the introduction of medium can finally neutralize the extreme state described by Heraclitus. In this kind 
of change, all living things maintain a relatively stable structure, attribute and hierarchy. For a period of time, the existence of an object will try to maintain a relatively constant structure and function, which is determined by the continuity of existence. So the existing things cannot be the existence and the nonexistence at the same time. In a range on the time axis, the existing things either exist or do not exist, or some aspects of the existing things either exist or do not exist. We can find that the theory of dualism appeared very early in the history of human thought, from which the contradiction thought and dialectic thought developed. However, all these ideas show a too simple understanding of the world. No matter how persuasive the metaphysical ideas are, eventually they will need to be brought down and integrate with the complex and chaotic world. From monism to dualism, then to the doctrine of "three" and "many". "Three" is the bridge to "many", because of the acknowledgement of "three", "many" is self-evident [7]. As Lao-Tzu said: "the One gave birth successively to two things, three things, up to then thousand."

Aristotle once said that everything has an opposite, that is, a contradiction-but in what sense can one distinguish one from the other, the big from the small and the so-called the equal? How does one distinguish between the large, the small, the equal, and their opposites [8]? Thus, he was the first person to put forward the idea of medium. He thought that there is a middle concept, "neither big nor small", between big and small, and that the middle concept which is "neither good nor bad" is the medium between good and bad [8].

In fact, we can conclude from Aristotle's theory that when the concept of medium was proposed, the opposite was no longer the most important part, because the only real existence is the medium between the two extremes, and the two extremes can never be reached. For example, there is no extreme big or small, and there is no extreme good or bad. These extreme concepts exist only on the information level, and the corresponding things belong to the nonexistence category. Therefore, it is not a medium that shares the two extremes-on the contrary, it is humans who summarize and imagine the two extremes and the two extremes are derived from the summarized experience in terms of the differences of things. Therefore, the so-called dualism, contradiction and opposite extremes do not exist in reality. They only exist in humans' imaginations and in the concept of information created by humans. Our understanding of the extremes comes from extrapolation of the differences and comparisons between things. These extreme concepts, such as infinitely big, infinitely small, infinitely high, infinitely low, etc., belong to nonexistence categories. It should be emphasized that Aristotle's concept of the medium is only an original form of medium thought, which is not equivalent to the concept of the medium in the philosophy of information.

\section{The Opposition and Mutual Transformation of Existence and Nonexistence}

The medium theory in the philosophy of information is a multi-medium construction theory in information epistemology [9]. It talks about the four mediums from the subject to the object, and vice versa. These four mediums are: the object information field, the physiological structure of the subject's nervous system, the cognition structure of the subject, and the use of material tools. They ensure the transmission of information flow, and they also choose, transform, match, recombine and reconstruct the information flow to a certain extent [10]. Here, the medium is no longer a general idea and concept, but becomes a kind of existence, having its own system, structure, and evolution process. In the ontology of information evolution, there is a unity of opposites between existence and nonexistence. However, the transformation mechanism between the two is different from the evolution mechanism of existence itself. The two are only at the level of conceptual attribution and do not interact with each other, so there is no medium between them.

Let us start with the transition between existence and nonexistence. As we can see from Figure 1 , existence is just a point on the timeline. This point represents the existence in the present time, while the existence moves and changes with time. In the evolution of existence itself, it comes from nonexistence in the transformation of time, and then returns to nonexistence. 


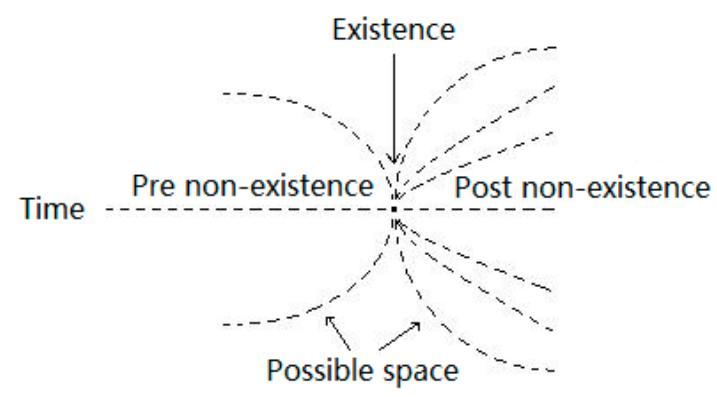

Absolute non-existence

Figure 1. Relation between Existence and Nonexistence [11].

Figure 2 shows the evolution of "existence $\mathrm{N}$ " into "existence $\mathrm{N}+1$ ". There is a solid line and two dashed lines in the figure, which represent three transformation relationships simultaneously. The solid line is the self-evolution relation of existence, and the two dashed lines are the transformation relation between existence and nonexistence.

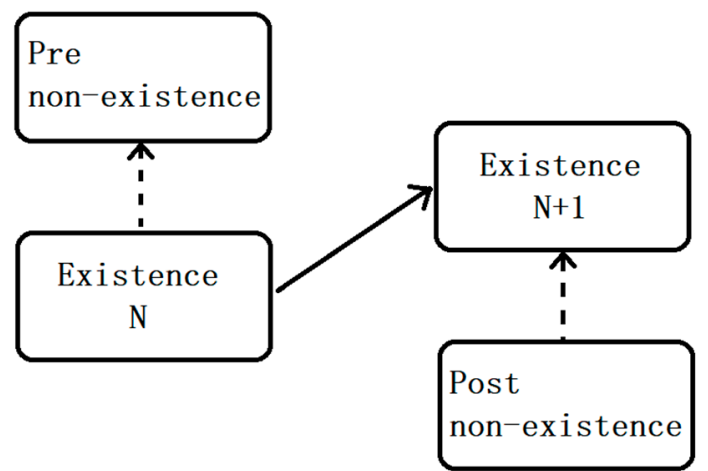

Figure 2. Transformation between Existence and Nonexistence.

So here we need to emphasize a few points:

First, the transformation between existence and nonexistence only applies to some aspects of existence (the four aspects of existence), but is not absolutely complete.

Second, the evolution of existence $\mathrm{N}$ into $\mathrm{N}+1$ is independent of nonexistence, and the evolution of existence is spontaneous.

Third, pre nonexistence and post nonexistence are identical in content and all nonexistences are identical. They are the absolute nothing, no difference and no content. The names are different simply because it is different from the transformational relationship of existence.

Fourth, the evolution of existence $\mathrm{N}$ represented by solid line into $\mathrm{N}+1$ is the result of interaction and requires medium, while the transformation of existence and nonexistence represented by the dashed line does not require a medium.

Conflicts of Interest: The author declares no conflict of interest.

\section{References}

1. Rosebery, U. Philosophy and Physics: The History of Atomism for Three Thousand Years; trans. Zhu Zhangcai; Qiushi Publishing House: Beijing, China, 1987.

2. Selections from Western Philosophy; compiled and translated by Department of Philosophy of Peking University; The Commercial Press: Beijing, China, 1981; Volume 1. 
3. The Ancient Greek and Roman Philosophy; trans. Department of Philosophy of Peking University; SDX Joint Publishing Company: Beijing, China, 1957.

4. Zhang, D. Outline of Chinese Philosophy; China Social Sciences Press: Beijing, China, 2004.

5. Wang, B. Lao Tzu the Scripture of Ethics Note; Zhonghua Book Company: Beijing, China, 2011.

6. Wu, T. A New Perspective on the Existence and Non-Existence; World Scientific Publishing Co Ltd.: Beijing, China, 2017.

7. Wu, K. The Thought, System and Complexity of Ancient Philosophy: Greece, China, India; The Commercial Press: Beijing, China, 2010.

8. Aristotle. Metaphysic; trans. Li Zhen; Shanghai Ren Min Publishing House: Shanghai, China, 2006.

9. Wu, K. Recognition: Information Construction Activities Relatively Moving in Multi-Level Intermediaries. J. Changsha Univ. S. Technol. (Social Sciences Edition) 1989, 6, 17-22.

10. Wu, K. Information Epistemology; China Social Sciences Press: Beijing, China, 2002.

11. Wu, T. A New Thinking Way about Being Based on the Philosophy of Information: The Being Hierarchy, Being and Non-being. Stud. Dialectics Nat. 2015, 11, 110-116.

(C) 2020 by the authors. Licensee MDPI, Basel, Switzerland. This article is an open access article distributed under the terms and conditions of the Creative Commons Attribution (CC BY) license (http://creativecommons.org/licenses/by/4.0/). 